\title{
Smart System for Rider Safety and Accident Detection
}

\author{
N. Srinivasa Gupta ${ }^{1}$, M. Nandini ${ }^{2}$, N. Sowjanya ${ }^{3}$, L. Pardha Sai ${ }^{4}$, K. Sai ${ }^{5}$. \\ ${ }^{1}$ Department of ECE,Raghu Institute of Technology, Visakhapatnam. \\ 2,3,4,5 Department of ECE, Raghu Institute of Technology, Visakhapatnam.
}

\begin{abstract}
The main objective of this project is to avoid accidents which are occurred due to negligence of not wearing the helmet, drunk and drive and over speeding. This might cause severe major accidents often results in death. The smart helmet consists of alcoholic sensor, RF transceiver, Vibration sensor and Arduino, wearing helmet shall be made mandatory by the rider. It consists of alcohol sensor which is employed to prevent drunk and drive scenario by checking the breath of rider, and stops the motor if they are drunken or not wearing helmet and also prevents over speeding and rash driving by alerting the rider with a message on LCD and reducing the motor speed with the help of PWM technique. The vibration sensor is placed in the helmet for accident detection, whenever the helmet strikes the ground vibration sensor will senses the vibration and thus the accident is detected. If the rider met with an accident, to the registered mobile number using GSM module, an alert message will be sent.
\end{abstract}

Keywords:-Vibration sensor, Arduino, Alcohol detection, Accident detection, Notification, GSM module, PWM technique.

\section{INTRODUCTION}

It is well known fact that many accidents and few results in death which are caused by two wheelers are due to rider negligence. The most common reason is not wearing helmet due to inconvenience created they purposely avoid helmet it is major reason of brain injuries which results to death. Moreover, drink and driving, over speeding are became other common problems for accidents. Now a day's technology is employed for solving all the modern age problems. So, the problems which are mentioned above are avoided and deaths are reduced with the assistance of technology. Many people die on roads every year that occur due to bike accidents nearly half of them in between 18-35 age group this motivates to develop a smart system. The main goal of this project is to make sure that rider is wearing his helmet [1] before ride and not driving the vehicle while rider is alcohol consumed and to prevent the rash driving [2]. Therefore, it's important that there should be a facility to attenuate the after effects of these accidents so accident detection is an important feature of our model it will notify to the registered contact numbers through GSM and GPS module [3] by which proper medical support are often given to the victim.

\section{DESIGN AND IMPLEMENTATION}

The system architecture of the Smart helmet for safety and accident detection.is shown within the below figure which comprises of the Arduino uno, Arduino mega, power supply and sensors. This system consists of two modules.

1. Transmitter side.

2. Receiver side.

\section{Transmitter side:}

This section consists of Arduino uno, RF transmitter, push button, alcohol sensor, vibration sensor. We will fix these on the helmet.

Block Diagram:

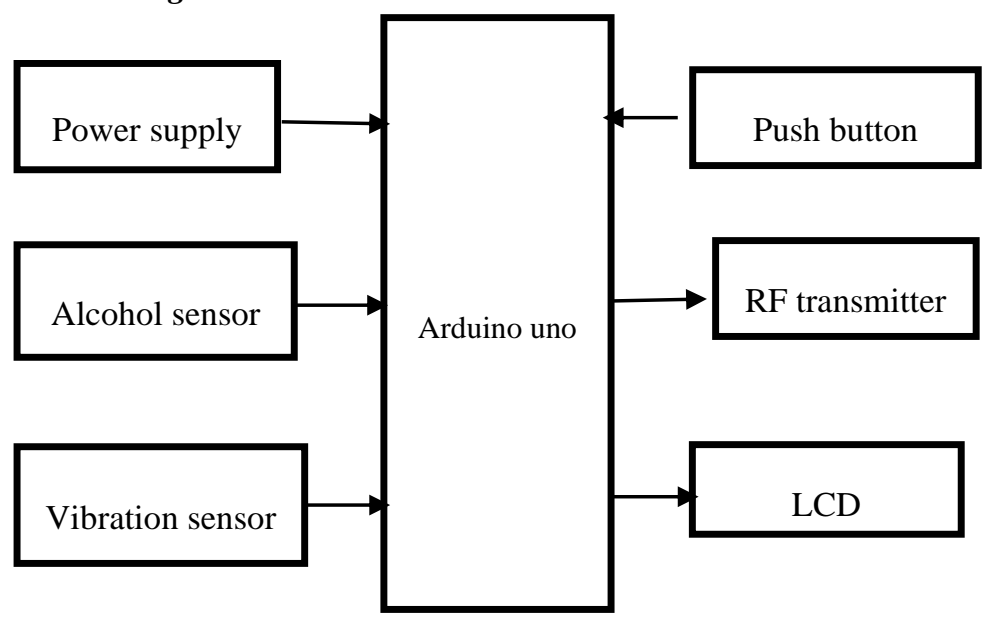

Fig 1: Transmitter side

a. Vibration sensor:

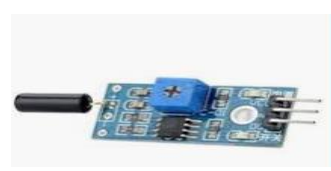

Fig 2: Vibration sensor (SW-420)

It is simplest sort of vibration sensor. It consists of small and thin pin with the centre of a coil spring. The spring is anchored at its base and therefore the other end isliberal to vibrate. If the vibration reaches sufficient amplitude, the spring touches the pin and completes the circuit between the two leads of the device.

\section{b. Alcohol sensor:}

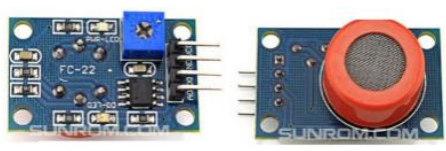

Fig 3: Alcohol sensor (MQ-3)

An alcohol sensor detects the attentiveness of alcohol gas in the air and an analog/digital voltage is an output reading it consists of Sno2 with the lower conductivity of clean air. The sensing range is from $0.04 \mathrm{mg} / \mathrm{L}$ to $4 \mathrm{mg} / \mathrm{L}$, which is suitable for breathalysers. 
c. Arduino UNO:

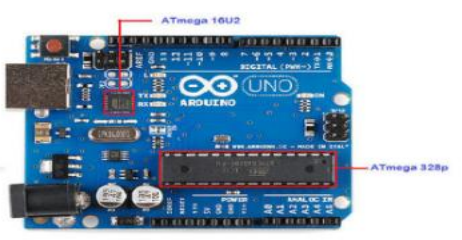

Fig4: Arduino uno

Arduino uno is a first-generation Arduino board. ATmega328p, it is the brain of the Arduino and it is a highperformance microcontroller which is cable of executing powerful instruction in single clock cycle.

\section{d. RF TransmitterSTT-433MHz:}

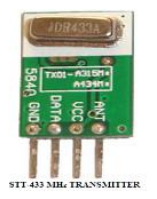

Fig 5: RF transmitter

The Arduino send the information to the transmitter with the assistance of encoder [4] the encoded message is sent to receiver with the help of antenna pin

\section{Receiver side:}

This section consists of Arduino ATMega, GSM, GPS module, $\mathrm{RF}$ receiver, driver module, dc motor, relay switch. We will fix this system on the bike.

Block Diagram:

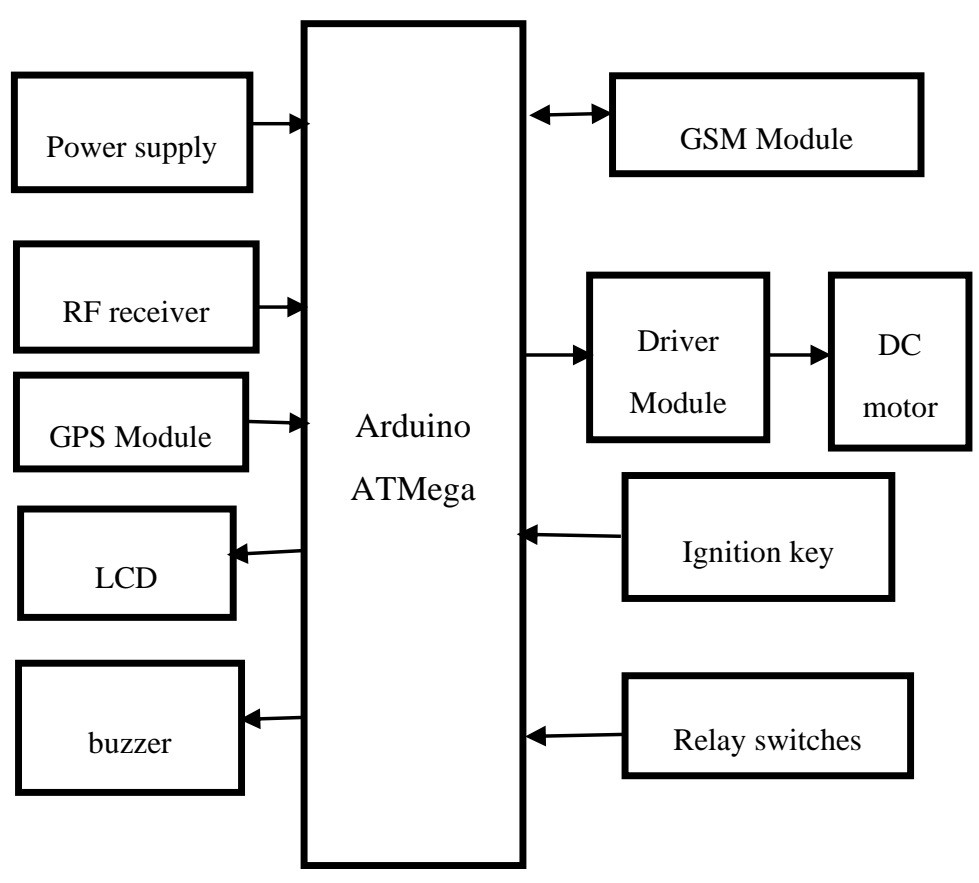

Fig 6: Receiver side a. ARDUINO MEGA 2560:

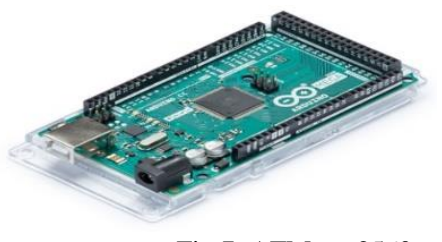

Fig 7: ATMega 2560

With all the capabilities of four Uno boards ccombined.Arduino Mega 2560 is a beefy microcontroller board based around the powerful ATmega2560 microprocessor. Arduino Mega sports $16 \mathrm{MHz}$ clocking speed, as well as $256 \mathrm{~KB}$ of flash, $8 \mathrm{~KB}$ of SRAM and $4 \mathrm{~KB}$ of EEPROM. Because of its brawnier processor, the Mega has 54 digital I/O pins and 16 analog pins.

\section{b. GSMmodem:}

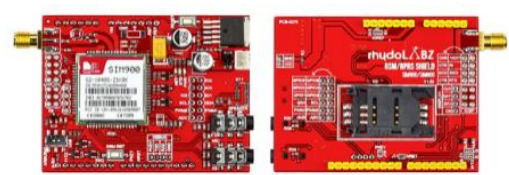

Fig 8: GSM module

GSM is an open, digital cellular technology used for transmitting data and mobile voices. It consists of a sim card port where the sim has to be inserted and can be operated employing the mobile operator.

\section{c. GPS Technology:}

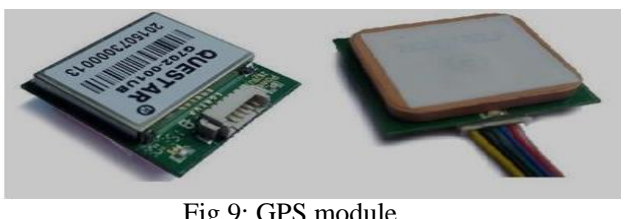

Global Positioning System (GPS) navigators use the mathematical technique of trilateration to determine user position, speed, and elevation. GPS navigators constantly receive and analyze radio signals from GPS satellites, calculating precise distance (range) to each satellite being tracked.

\section{d. RF Receiver STR-433MHz:}

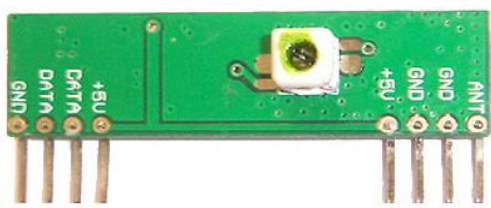

Fig 10: RF receiver

The data transmitted into the air is received by the receiver. The received data is taken from the data line of the receiver and is fed to the decoder. The output of decoder is given to microcontroller then data is processed according to the application. 
e. Motor driver:

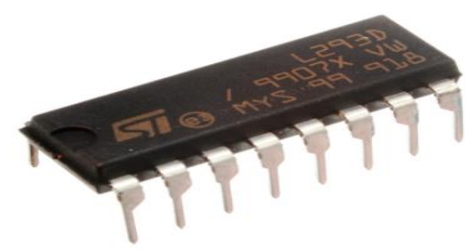

Fig 11: driver module

Motor driver is basically a current amplifier which takes a low-current signal from the microcontroller and provides a proportionally higher current signal which can control and drive a motor.

\section{SYSTEM AND IMPLEMENTATION}

The sensors like vibration sensor and alcohol sensor in the transmitter section are fixed to Arduino Uno to the helmet to check the condition and these signalling is sent through the RF Technology [6] to the Arduino ATMega to start the bike for the rider which is connected to receiver side.

While in the receiver section Arduino ATMega receives the RF signal, relay switches for the speed limit control, ignition key, GSM and GPRS for the location identification and message notification if in case any accident occurs. The speed controlling is done by the relay switches with high, medium and low.

The initial conditions like helmet worn by the rider and low alcoholic consumption are make sure to allow bike to start for the rider safety and if any case of increasing the speed it will notify initially and would be automatically decreases the motor speed gradually. If any removal of the helmet or alcoholic consumption the bike would be automatically stops and would be notify if alcohol senses more.

\section{METHODOLOGY}

This smart system is cost effective and provides quick accident detection and notification. The system implementation basically involves two Sections. Initially the ignition key should be in on state.

\section{a. Transmitter side:}

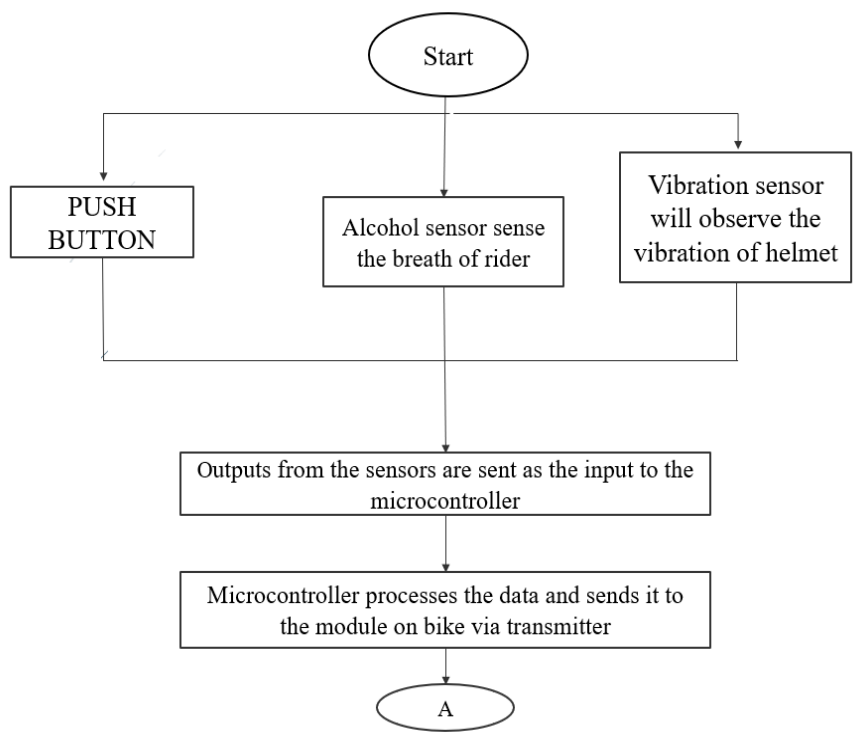

Initially the push button should be pressed this will happens only when the rider wears the helmet and then the alcohol sensor will check the alcohol content in the rider's breath. Vibration sensor will observe the vibrations. The sensors output is given as input for microcontroller which is fixed to the helmet. The microcontroller will process the information and sends data to the transmitter side which is fixed to the bike.

\section{b. Receiver side:}

The data sent by the transmitter is given to the microcontroller

through $\mathrm{Rf}$ receiver.the microcontroller decision is based on the transmitter section.

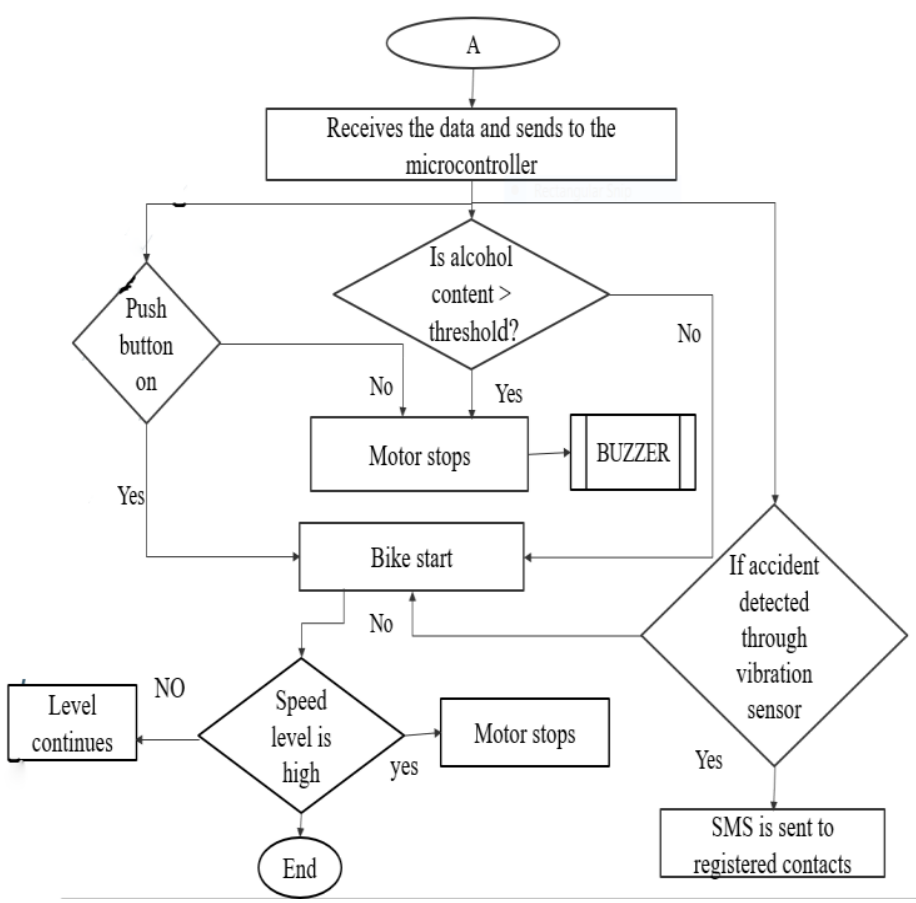

Fig 13:Flow chart of receiver side

The ignition of the bike starts only when transmitter side satisfies these three conditions, they are.

- The push button should be in on state.

- The alcohol sensor output should be negative and.

- The Vibration sensor doesn't observe any vibrations.

When the output of the transmitter side satisfies these three conditions then only the bike ignition will start. Otherwise it will be on off state, and therefore the buzzer will produce sound.

If the rider exceeds the specified speed limit then it will alert the rider with a message on LCD, even after the rider is not reducing the speed after sometimes the motor speed is automatically reduced by using PWM technique, and therefore the bike will stop.

When the vibration sensor absorbs the vibrations, it means the accident is occurred [7]. Then automatically the message notification with the location of the accident area is sent to the registered numbers through GSM and GPS module. So, the person can be provided with proper medical attention. 


\section{EXPERIMENTAL RESULTS}

The system design is capable of making sure that rider wears helmet and not riding the vehicle in drunk state. if these conditions not satisfy then therefore the motorwon't start and the reason for it is displayed On LCD as shown in below figures.

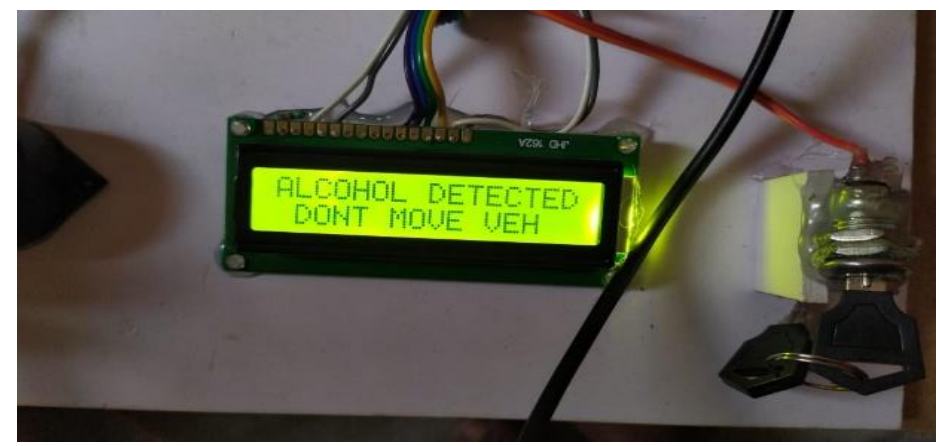

Fig 14: Alcohol is detected and therefore motor stops

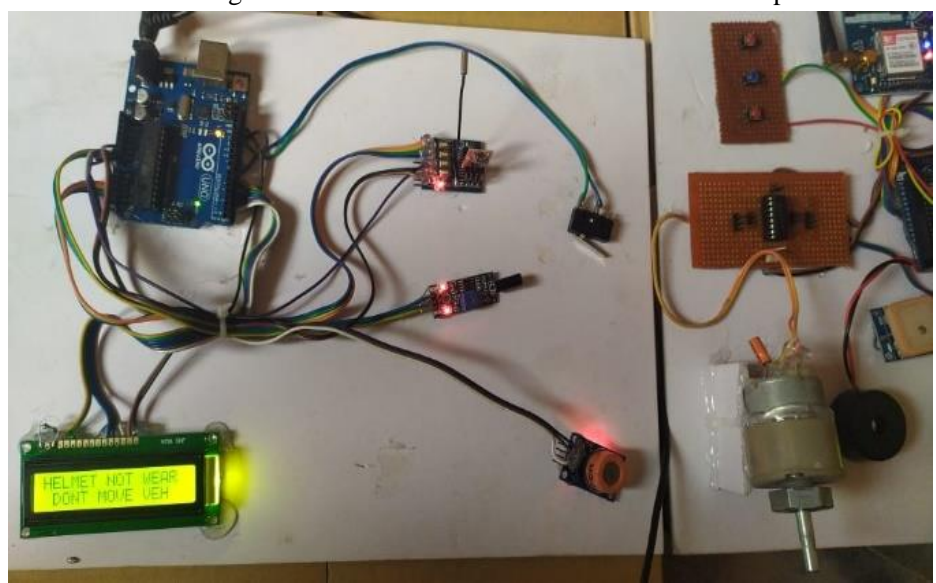

Fig 15: when helmet is not worn by rider and vehicle stops

If the rider increases the speed more than the specified level. Then the alert message is sent to the rider through LCD. Even then speed not reduce then the motor is controlled automatically after a specified time

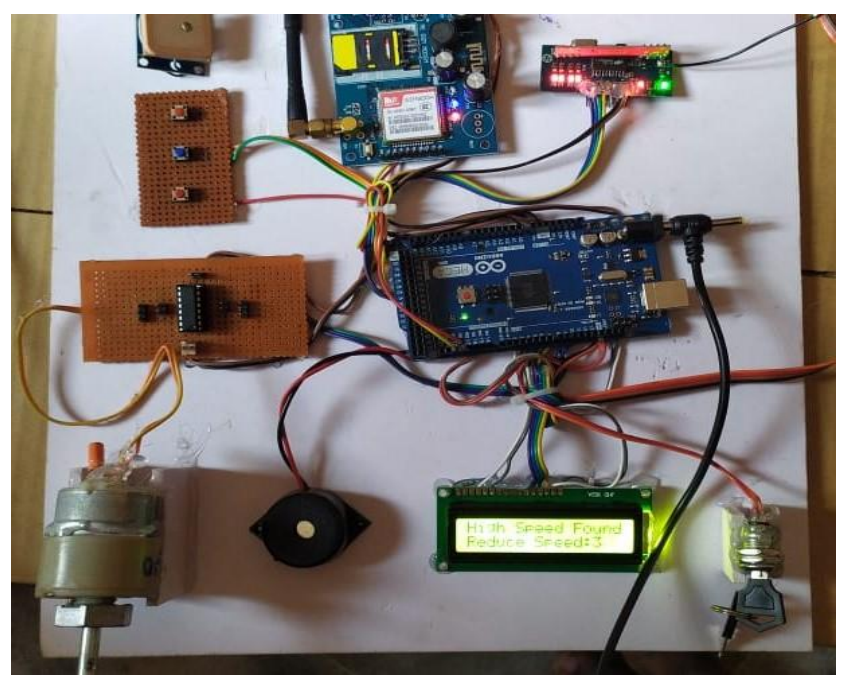

Fig 16: high speed is found message alerts to reduce speed
When the accident and alcohol is detected then the message is sent to registered contact numbers within a fraction of seconds as show in the below figure with the location.

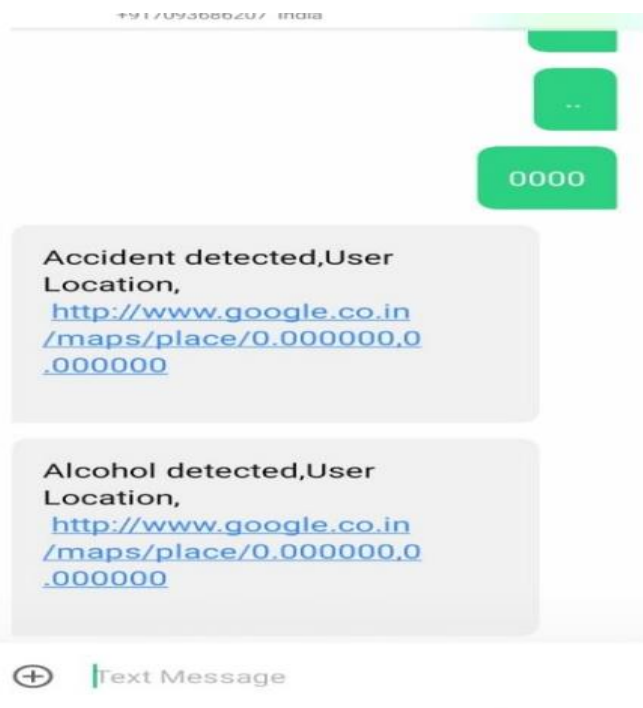

Fig 17: Message notification

\section{CONCLUSION}

The system designed is very efficient and useful, it is very accurate for checking the condition whether the rider worn the helmet and alcohol is not consumed. The system is extremely successful in reducing rash driving by monitoring the speed. Accident detection is an important feature it's successful in notifying the accident with location through GSM and GPS module to the registered numbers. So, the smart system is efficient and provides safety to the rider and reduces the consequences of accidents.

\section{REFERENCES:}

[1] Aashaadha, Anita, Anusha, Prema, Rumana Anjum (2019), "Smart helmet for Safety and accident detection using IOT". International research journal of Engineering and technology (IRJET), Issue: 03, Pages: 04.

[2] Harshith H, Lokesha G.N, Kishore Kumar R, Deepika (2019), "IOT Based Delivery Boys Safety Control and bike analyser". International Journal of Scientific Research \& Engineering Trends (IJSRET), Issue: 02, Pages: 04.

[3] Manjesh N, Prof. Sudarshan Raj (2014), "Smart Helmet Using GSM \& GPS Technology for Accident Detection and Reporting System", International Journal of Electrical and Electronics Research, Issue: 04, Pages: 06.

[4] Professor Chitte P.P, SalunkeAkshay S, Thorat Aniruddha, N Bhosale (2016), "Smart Helmet \& Intelligent Bike System", International Research Journal of Engineering and Technology (IRJET), Issue: 05, Pages: 05.

[5] Nitin Agarwal, Anshul Kumar Singh, Pushpender Pratap Singh, Rajesh Sahani(2015), "SMART HELMET", International Research Journal of Engineering and Technology, Issue: 02, Pages: 04.

[6] Jennifer William, Kaustubh Padwal, Nexon Samuel, AkshayBawkar, SmitaRukhande (2016), "intelligent Helmet" International Journals of Scientific \& Engineering Research, Issue: 03, Pages: 04.

[7] C.Prabha, R.Sunitha, R.Anitha (2014), "Automatic Vehicle Accident Detection and Messaging System Using GSM and GPS Modem", International Journal of Advanced Research in Electrical, Electronics and Instrumentation Engineering, Issue: 07, Pages: 05. 